Public discourses of Ebola contagion and courtesy stigma: The real risk to international health care workers returning home from the West Africa Ebola outbreak?

Gee, Stephanie; Skovdal, Morten

Published in:

Qualitative Health Research

DOI:

$10.1177 / 1049732318759936$

Publication date:

2018

Document version

Peer reviewed version

Document license:

Other

Citation for published version (APA):

Gee, S., \& Skovdal, M. (2018). Public discourses of Ebola contagion and courtesy stigma: The real risk to international health care workers returning home from the West Africa Ebola outbreak? Qualitative Health Research, 28(9), 1499-1508. https://doi.org/10.1177/1049732318759936 


\title{
Public discourses of Ebola contagion and courtesy stigma: The real risk to international health care workers returning home from the West Africa Ebola outbreak?
}

\author{
Stephanie Gee ${ }^{1,2 \S}$ and Morten Skovdal ${ }^{2}$
}

1 School of Health and Related Research, University of Sheffield, United Kingdom

2 Department of Public Health, University of Copenhagen, Copenhagen, Denmark

$\S$ Corresponding author: Stephanie Gee

Department of Public Health

University of Copenhagen

Øster Farimagsgade 5

Copenhagen, 1014, Denmark

stephie.gee@gmail.com

E-mail addresses of authors:

SG : stephie.gee@gmail.com

MS:m.skovdal@gmail.com

\begin{abstract}
This article explores the homecoming experiences of international health care workers who responded to the 2014-2016 West African Ebola outbreak. Interviews with 11 front-line international medical staff were undertaken and data thematically analysed. It was found that international health care workers faced an unforeseen risk of stigmatization upon their return home, related to others' fears of their infectious status. Media representations of the disease appear to have played a significant role in heightening societal perceptions of the risks associated with the returning health care workers, resulting in public hostility towards them. For participants, these social risks overtook concerns about biological risks during the immediate post-mission period. The participants developed different strategies to cope with courtesy stigma, either by rationalizing stigmatizing attitudes, educating people, or simply through an avoidance of others.
\end{abstract}

Key words: Courtesy stigma; Ebola; Health care workers; Risk perception; Stigma; West Africa 


\section{INTRODUCTION}

Health care workers are on the frontline during infectious disease outbreaks, taking significant risks in order to provide life-saving health services. While the general public respect the courage of health care workers in responding to unpredictable and novel disease outbreaks, we will in this article draw on the experiences and perceptions of international health care workers returning from Ebola missions in West Africa to argue that the general public paradoxically co-constructs a latent form of risk, namely a 'courtesy stigma' against health care workers. To make this argument, we examine the following questions: How are stigmatizing attitudes generated, perpetuated and translated into behaviours that impact international health care workers? What are the perceived drivers of courtesy stigma? How do health care workers experience and cope with courtesy stigma? What are the implications of courtesy stigma to their psychosocial well-being? How does this risk of courtesy stigma influence their willingness to respond to future disease outbreaks?

\section{Health workers and courtesy stigma}

The seminal work on stigma by Erving Goffman (1963) guides this study. Goffman (1963) defines stigma as a discrediting attribute that isolates individuals or communities of people who are perceived to be a threat to public order. It involves a process of 'othering' that results in individuals being disqualified from full social acceptance. As health care workers are not considered a stigmatized group, per se, the stigma they experience is through their association with a stigmatized individual or group (Phillips, Benoit, Hallgrimsdottir, \& Vallance, 2012). Goffman (1963) refers to this stigma-by-association as 'courtesy stigma'.

Ebola outbreaks are characterized by significant rates of infection and death in health workers, and those working during the West African outbreak were found to be 21-30 times more likely to become infected than the general population (WHO, 2015). As they dealt with significant personal risks, patient suffering, and public fear, local doctors and nurses who responded to Ebola virus disease (EVD) outbreaks experienced feelings of fear, panic, exhaustion, and frustration, at the same time demonstrating altruism in their commitment to patients (Bell et al., 2017; Guimard et al., 1999; Hewlett \& Hewlett, 2005; Kinsman, 2012). Stigma of health care workers by local community members is also a common observation during such outbreaks. Guimard et al (1999) noted during the 1995 Ebola outbreak in the Democratic Republic of the Congo that health care workers had their property destroyed, were expelled from their home communities, and had stones thrown at them. Rumours that medical staff were purposefully spreading the infection or profiting from the bodies of victims further heightened negative reactions towards them by local communities (Guimard et al., 1999; Hewlett \& Hewlett, 2005). As a result, Kinsman (2012) argues, local health care workers have been profoundly psychologically affected during these outbreaks. The 2014-2016 West African outbreak saw similar fear reactions, including beliefs that foreign aid workers were intentionally spreading the disease 
(Nossiter, 2014), fears that resulted in the killing of an entire team of outbreak investigators by suspicious villagers (BBC, 2014).

Other infectious disease outbreaks have also resulted in stigmatization of health care workers. The Severe Acute Respiratory Syndrome (SARS) outbreak of 2003 provides a comparable example, as it was also a relatively new and unknown virus resulting in high rates of nosocomial and health care worker infections. The few studies that have examined the experiences of front-line health care workers found stigma to be a common finding. Koh et al. (2005), in their survey of 15,000 hospital staff in Singapore found that despite a feeling of social recognition, a significant proportion of staff (49\%) and their families (31\%) experienced social ostracization. Similarly, a survey of stress reactions in health care workers involved with SARS in Taiwan found that $20 \%$ of hospital staff felt stigmatized in their neighborhoods, and $9 \%$ were reluctant to go to work or had considered resignation (Bai et al., 2004). Nickell et al. (2004) in a survey among staff in a Toronto hospital during the SARS outbreak, found between $29-45 \%$ of respondents experienced emotional distress with a key contributing factor being the concern of being treated differently by others due to working in a hospital responding to SARS. In response to such perceptions, rooted in courtesy stigma, several studies demonstrate an avoidance reaction on the part of the health workers. A survey in Hong Kong showed that health care workers exhibited fear of transmitting SARS to family members, colleagues or friends, and in response many chose to live away from home and isolated themselves during the outbreak (Ho, Kwong-Lo, Mak, \& Wong, 2005). Tam et al. (2004), also in Hong Kong, corroborated the feelings of personal vulnerability as well as the avoidance of social contacts by health care workers.

As pandemics grow in global size and reach, the need for a willing and able international health workforce response becomes increasingly apparent, making the dimension of international health workforce mobility a particularly pertinent one to explore. In addition to thousands of local staff, the West African EVD outbreak also drew over 2000 foreign medical staff from 40 different organizations and involved 66 different Ebola Treatment Centres (ETCs) (Vetter et al., 2016). The experiences of international responders may be notably different from local health care workers in that they navigate different risk landscapes at the epicenter (Gee \& Skovdal, 2017a) and they face unique social contexts in their home countries upon return. Two qualitative studies have noted the homecoming experiences of international health care workers responding to the Ebola outbreak. An occupational health review of international delegates with the International Federation of the Red Cross found that returning delegates from Ebola missions faced stigmatization by members of the public and many planned to self-isolate in response to public hostility upon return to their home country (Haggman, Kenkre, \& Wallace, 2016). Similarly, Gershon et al.'s study of US health volunteers deployed in the Ebola response found the return home to be very stressful, as they experienced isolation and difficult interpersonal interactions including facing avoidance, anger and resentment, as well as 
stigmatization against both themselves and their family members (Gershon, Dernehl, Nwankwo, Zhi, \& Qureshi, 2016). The difficulties in the return home made a number of participants doubt their willingness to do another similar deployment in the future. Our study looks to develop this small body of work by exploring the homecoming experiences of international health care workers, as well as unpacking some of the social dynamics that may have contributed to the development of stigma in this group.

\section{METHODOLOGY}

It is apparent from the above discussion that the homecoming experience is significant and can have an inevitable effect on returning health care workers. To understand how these effects come to the fore, we set out to examine how discursive constructions, intersubjectivity, and body converge to shape how health care workers perceive and make sense of their experiences of returning home.

\section{Study setting and participants}

Semi-structured interviews took place from July 2014 through to January 2015 with analysis happening during and after data collection. Ethical approval was obtained from the University of Sheffield School of Health and Related Research. Informed consent, declaring the intents and purposes of the study, was sought from participants with assurance that anonymity would be maintained. Eleven front-line health care workers of seven different nationalities who had recently returned from working in the West Africa Ebola outbreak were recruited using a snowball sampling approach, a method that draws on natural social networks, 'snowballing' out from an initial contact (Sixsmith, Boneham, \& Goldring, 2003). Recruitment also occurred by placing notices on social media sites. Participants were recruited to include those who worked directly with affected patients, ensuring participation from both doctors and nurses of both genders, and did not include non-medical auxiliary staff or people in management positions who did not provide patient care.

The majority of participants worked within an Ebola Management Centre (EMC), with several others conducting contact tracing or outreach in local communities. Nationalities of participants included Canadian (2), Japanese (2), Nigerian (1), Ugandan (1), Italian (2), Danish (2), and US American (1). The participants had a mean of 10 years professional experience (range 5-22 years) and consisted of six nurses, four doctors/clinical officer, and one public health specialist. The mean age was 35 years old (range 28-46). See Table 1 for more information about the participants. Only one participant was married, although several others were in longterm relationships, and only one participant had children. 
Table 1: Group data of study participants

\begin{tabular}{|c|c|}
\hline Characteristics & Number \\
\hline \multicolumn{2}{|l|}{ Gender } \\
\hline \begin{tabular}{l|l} 
& Female
\end{tabular} & 9 \\
\hline \begin{tabular}{l|l} 
& Male \\
\end{tabular} & 2 \\
\hline \multicolumn{2}{|l|}{ Age } \\
\hline \begin{tabular}{l|l|} 
& $20-29$ \\
\end{tabular} & 4 \\
\hline $30-39$ & 5 \\
\hline \begin{tabular}{l|l}
$40-49$ \\
\end{tabular} & 2 \\
\hline \multicolumn{2}{|l|}{ Profession } \\
\hline \begin{tabular}{l|l|} 
& Nurse \\
\end{tabular} & 6 \\
\hline Doctor & 3 \\
\hline Clinical Officer & 1 \\
\hline \begin{tabular}{l|l|} 
& Public Health Specialist \\
\end{tabular} & 1 \\
\hline \multicolumn{2}{|l|}{ Years of professional experience } \\
\hline \begin{tabular}{l|l|} 
& $<10$ \\
\end{tabular} & 5 \\
\hline \begin{tabular}{l|l} 
& $>10$ \\
\end{tabular} & 6 \\
\hline \multicolumn{2}{|l|}{ Number of Ebola missions } \\
\hline \begin{tabular}{l|l} 
& 1 \\
\end{tabular} & 7 \\
\hline 2 & 3 \\
\hline \begin{tabular}{l|l} 
& 5 \\
\end{tabular} & 1 \\
\hline \multicolumn{2}{|l|}{ Nationality } \\
\hline \begin{tabular}{l|l} 
& American \\
\end{tabular} & 1 \\
\hline Canadian & 2 \\
\hline Danish & 2 \\
\hline Italian & 2 \\
\hline Japanese & 2 \\
\hline Nigerian & 1 \\
\hline Ugandan & 1 \\
\hline
\end{tabular}

\section{Data collection and analysis}

The majority of interviews were carried out using Skype $(n=9)$, with the remainder done face-to-face $(n=2)$. Skype served as an online research tool, allowing us to interview geographically dispersed participants (Germain, Harris, Mackay, \& Maxwell, 2017). The topic guide (see supplementary file) was followed, which allowed for a dialogical interview, with participants guiding the direction of the interview. This had the advantage of greater emphasis being placed on the perspectives of the participant rather than on the researcher's concerns (Bryman, 2015). Participants were asked questions asked about their general experiences with regards to perceptions of risk, taking into account periods of time before, during, and after their mission. At a sample size of eleven, many themes began to reappear in the interviews, providing us with enough information power to proceed with the analysis (Malterud, Siersma, \& Guassora, 2016). This article represents a sub-set of the data focused on the post-mission period. The duration of the interviews averaged 1 hour 50 minutes, and took place within two months of participants' return from West Africa.

Analysis took place both during and after the interviews. During the interviews, the first author sought to make interpretations of what was being said, noting connections between their individual cognitions, experiences and sense-making, asking follow-up 
questions, either to help the interviewee see connections or to get their feedback on the interpretations (Kvale, 1983). The during-interview analyses were followed by more conventional qualitative thematic analysis of interview transcripts, involving a systematic process of coding and identifying cross-cutting themes within the data set (Skovdal \& Cornish, 2015). Interview data was first anonymized, transcribed verbatim into text, then imported into the software NVIVO 11. Next the transcripts were read repeatedly in their entirety, to establish familiarity and to get an idiographic understanding of each study participant before attempting a cross case analysis. Informed by interpretations made during the interviews, codes were derived from the data set rather than being predetermined by theory. The interviews were interrogated, line-by-line, until the entire data set was systematically coded for content (Richards, 1999). A thematic map was developed through the categorization of these initial codes into broader organizing themes, and the organizing themes into three global themes (Attride-Stirling, 2001). In this article we focus on one of the three global themes (see Table 2). The remaining two global themes have been reported elsewhere (Gee \& Skovdal, 2017a, 2017b). Table 2 outlines the development of the global theme from organizing themes and primary codes, and forms the structure of the findings section, which sequentially advances the analysis (Simons, Lathlean, \& Squire, 2008), and presents representative quotations for each of the emerging themes. 
Table 2: Thematic Analysis: from codes to global theme

\begin{tabular}{|c|c|c|}
\hline Global Theme & Organizing theme & Basic themes (codes) \\
\hline \multirow{10}{*}{$\begin{array}{l}\text { Experiences on } \\
\text { returning home }\end{array}$} & \multirow[t]{2}{*}{$\begin{array}{l}\text { "The media was creating this hysteria": } \\
\text { Media representations of the outbreak }\end{array}$} & $\begin{array}{l}\text { Media representations - } \\
\text { exaggerated and focused on the } \\
\text { West }\end{array}$ \\
\hline & & Public perceptions \\
\hline & \multirow{5}{*}{$\begin{array}{l}\text { "They wouldn't hug me": Manifestations } \\
\text { of courtesy stigma }\end{array}$} & Social exclusion \\
\hline & & $\begin{array}{l}\text { Negative comments from } \\
\text { family/friends/public }\end{array}$ \\
\hline & & Fear of public/media exposure \\
\hline & & Family fears \\
\hline & & Family stigma \\
\hline & $\begin{array}{l}\text { "I just decided to avoid people": Coping } \\
\text { with courtesy stigma }\end{array}$ & $\begin{array}{l}\text { Coping with stigma: avoiding; } \\
\text { educating; rationalizing }\end{array}$ \\
\hline & \multirow[b]{2}{*}{$\begin{array}{l}\text { "It was kind of playing with my mind": } \\
\text { Impact of courtesy stigma }\end{array}$} & $\begin{array}{l}\text { Psychological impacts } \\
\text { (frustration, sadness, anger) }\end{array}$ \\
\hline & & $\begin{array}{l}\text { Practical impacts (housing, } \\
\text { missing social events, declining } \\
\text { future Ebola missions) }\end{array}$ \\
\hline
\end{tabular}

\section{FINDINGS}

“... you come back and it is like you are the victim." (Doctor, Uganda)

As the returning health care workers moved from West Africa back to their home countries, they also moved from being individuals preoccupied with managing their personal risks while caring for the sick, to becoming the embodiment of contagion themselves, threatening the perceived security of not only their family and friends, but of entire countries. A social amplification of the risk (Kasperson et al., 1988) of Ebola transmission appears to be occurring through media-fueled fear reactions in the public resulting in the creation of social distance through courtesy stigma.

\section{"The media was creating this hysteria": Media representations of the outbreak}

A key factor in the public's fear reaction seems to have been related to media coverage of the outbreak. Overall participants felt that the media misrepresented the 
outbreak in two key ways - the first was by exaggerating and generalizing the situation in West Africa, leading to apocalyptic impressions:

Because I think that the media made it seem that it was such a dangerous place to go, so apocalyptic. And it's true in one sense, that in September Monrovia was really bad, people were dying outside the EMC, but we are not there anymore, and that is also not the reality of every single Ebola Management Centre. (Nurse, Italy)

Secondly, participants were disturbed by the media focus on unrealistic risks to the West, including the risk from returning health care workers like themselves, while the reality of the ongoing crisis in West Africa was made secondary:

I mean I felt upset that people were not considering that other people in another part of the world were suffering and dying, they were just worried for themselves, for possibly getting sick, where the possibility is very, very, very, low... And how the media could move the focus of attention from actual problems we have here, to "Oh Africa is affecting us with their problems", rather than "Africa has this problem and needs support". (Nurse, Italy)

There was one person who was put in a prison for a day because he was coming from West Africa, but he wasn't sick or anything... the media was creating this hysteria and people were completely feeding into it. Keeping their kids home from school, sending my sister home from work.... It was disgusting to me, and I am not sure I will ever understand at what point people stop caring about each other. (Public health specialist, USA)

These media representations of Ebola and focus on risks to the West may have contributed to public fear and subsequent stigmatization of health care workers, which arose as a surprisingly common issue for participants.

\section{“They wouldn't hug me": Manifestations of courtesy stigma}

The return home was a period of complex emotions. While in most cases the reaction to their return from friends and family was mixed, with many being very supportive and welcoming, at the same time the large majority of participants had experiences of family and friends who avoided them during their 21-day observation period and beyond. The knowledge about the length of the incubation period and that asymptomatic persons cannot transmit the disease did not seem to alleviate fear and avoidance behaviours in many social contacts of participants.

I had an interview on national television just after coming home. Then the next day my uncle called me and said that he would like me not to attend my 
Grandmother's 90th birthday the following week because he was afraid people would not attend the party because they would be afraid of getting Ebola. And I thought, "Oh no"...And they were not able to understand, or did not want to understand, when I explained to them that you cannot infect other people if you don't have any symptoms. But they just said, some people have seen you on TV and they may be scared. (Doctor, Denmark)

So it was actually more difficult than I thought it would be. And also my Mom's colleagues saying, "Why can she return? She can contaminate everybody", and then my Mom saying to me, "Yeah why don't you...shouldn't you be isolated?". I was like, ok, we talked about this. But she was also being caught up in this thing where people keep saying that...you know it grew, it got bigger and bigger. (Nurse, Denmark)

Some of my friends were great, but some of my friends were afraid to meet me, even after the 21 days. They wouldn't hug me, they wouldn't even clink glasses with me for cheers. (Public health specialist, USA)

Securing accommodation became an additional stressor for a number of participants, as stigma and fear around their potential infectious nature meant some family, friends and colleagues did not want the returning health care worker to live with them upon their return, resulting in feelings of disappointment and anger. A nurse describes how her parents' fears were fuelled by media reports from the USA, which resulted in her being banned from the family home after her mission, despite it being Christmas:

I think it hyped up exponentially when Craig Spencer got sick and when Kaci was caught, sorry not caught, when she was put in mandatory quarantine. My father was basically telling me the news every day "Did you know there was a doctor who got sick?" "Did you know she didn't abide the law and that she didn't put herself in quarantine?" ... and the fact that my own family didn't understand, and that I couldn't go home was quite upsetting. I was pretty angry. (Nurse, Canada)

Interestingly, dealing with negative media exposure, social stigma and hostility became the dominant perceived 'risk' for the health care worker during these 21 days, often superseding health concerns of developing Ebola. One participant avoided returning to Canada after her mission as she was worried about the fearful atmosphere there, instead choosing to pass the 21 days in Spain. However, she did not escape the public panic in Spain:

S: Were you worried or concerned at that time?

Yeah. But not about Ebola. I wasn't worried about Ebola. I was worried to have a fever because of the cold, and to create... Because in Spain it was like that. We were watching the news, there was someone coming back, an Ebola 
suspect and there were like 50 journalists around the hospital. It was crazy. It was really crazy. It was number one among all the news, over TV, over radio, "Ebola suspect" and it was a panic. Journalists were interviewing people and they were so upset - "They should not go in Spain, they should stay in their country". I was just afraid that that would happen to me. I knew I didn't have Ebola but just if I was a suspect, if I had that fever, I would have to go to the hospital and tell them, and I was so afraid, yeah...Yeah this was the most stressful part -the runny nose. (Nurse, Canada)

And if I were to develop symptoms, it wouldn't matter if I didn't see a single person, if I am in my house for 21 days and I get sick and I have to go to a hospital, then you know, everything in my house gets destroyed, if my dog was around after the Spanish nurse had her dog killed... You know having my things destroyed and my dog killed and getting hate mail and being told I am a horrible selfish person for bringing this back. I mean its...it terrifies me. It terrifies me more than being in the field. Much, much more. (Public health specialist, USA)

A sense of trepidation is apparent in the voice of this participant. What one nurse feared was not the deadly outcome of Ebola, but the negative social exposure that would accompany an Ebola infection:

Because if I got Ebola, in this small country, my name -because I was on news already- so if I got Ebola, they know my name. They know my family. They know where I live. (Nurse, Japan)

\section{"I just decided to avoid people": Coping with courtesy stigma}

The health care workers reacted to the social stigma they faced in three main ways: by rationalizing people's reactions; by trying to educate others; and by avoiding. To rationalize people's behaviour, the health care workers try to put themselves in the shoes of the public.

I mean, the way I handled it, was I just said, if I were in their shoes, maybe I would have done the same thing. You know? But of course I knew they were ignorant. And people were scared. (Doctor, Nigeria)

Actually I was not happy that I was not welcomed to Japan, completely. But at the same time I can understand how they feel, because it's really... Ebola is really new to them. It's ok for me because I am a bit familiar with Ebola, more than them. Because I have experience, but they don't have any experience, treating patients. So I can understand how they feel. (Nurse, Japan) 
Many participants tried to educate family and friends, as well as the public through media appearances about the situation in West Africa and why they should not be worried about viral transmission risks from asymptomatic persons such as themselves. One participant who could not find a place to stay following the mission was placed in the home of a fellow Médecins Sans Frontières (MSF) staff member, who despite working for the organisation did not appear comfortable, needing ongoing education and assurances:

But sometimes she was uncomfortable. She said to me "Someone told me I should disinfect my bathroom and toilets. Do you think it is necessary for me to do that?" So I had to start educating her again. It was a difficult moment. (Doctor, Nigeria)

However, the most common reaction to the stigma and public hostility participants were facing was by avoiding others. Many participants internalized some of the public sentiment about their perceived threat to others:

I didn't want to complicate my situation at that time. So I just decided to avoid, to avoid people. Tried to avoid as much as I could. (Doctor, Nigeria)

I also got that feeling of people being so afraid of me, that I was thinking, maybe I shouldn't go out. So I started isolating myself, which is what I was saying all the time we don't have to do and all of a sudden I felt that I had to do it because 'what if'? (Nurse, Denmark)

The coping strategy of 'avoiding' extended even to avoiding their home country upon completing their mission. This applied primarily to participants from North America. The first participant quoted below decided to stay in Europe after her second mission due to the difficult time she had had in the US following her first mission:

I thought - "I can't handle this anymore. I don't want to be in the US". And so, it was a very hostile environment and my family was afraid because all these things had been on the media. And they also faced a lot of stigma. My sister was sent home from work and things like that. (Public health specialist, USA)

My first thought was that I wanted to come home to Canada... but I was asking, "Should I stay in Europe?" just because I didn't have a place to go to and just because there is just so much more hype and paranoia in North America. (Nurse, Canada) 


\section{"It was kind of playing with my mind": Impact of courtesy stigma}

The public amplification of risk and the resulting stigma had significant impacts for many of the participants, both psychologically and practically. Psychological impacts included feelings of frustration, disappointment, depression and anger:

You are down. You thought you were going to give a helping hand, you thought you were doing something positive, not knowing you were carrying a cross on your back, that you are isolated, your friends even try to look at you from afar, much as they call you by name I don't think they'd love to shake your hands. Even medical personnel fundamentally don't understand. (Doctor, Uganda)

So it was kind of playing with my mind as well after all this. Also because on Facebook, MSF has this, they pop up with things saying "Donate" or "Ebola is Real" or they have all these commercials for them of course, and on the Ebola ones, people were commenting, saying "Why do the people need to return and contaminate all of us in Denmark?" and "They should be placed in a camp somewhere for those 3 weeks" and since we were only about 5 people returning, it was, it felt personal to me... and I actually got angry. This is Denmark, we should know better. (Nurse, Denmark)

In addition to making the return home difficult for most, stigma also prevented at least three participants from returning for subsequent missions. A nurse, who prior to leaving for the mission had felt that the risks were no different than any other mission, realized the complex social nature of the risk upon her return home:

Ebola is not a simple disease. So, if I am infected, maybe my family members will be infected as well. And then, the family, maybe family will have to move away from their current house because of the mass media. It's totally different if I die due to bomb blast, but if I die with Ebola, or if I can be contagious to another person, it is not a problem of only myself. So it can be affected to the others, a lot of people. Not only the disease itself, but the social status, or financial problem as well. So that is why, officially, my father didn't agree with me when I asked them to go for another mission. (Nurse, Japan)

In terms of public health response capacity, this impact on willingness to respond may be significant. It is also apparent that both public and family perceptions can play a significant role in the health care worker's willingness or ability to respond. These perceptions may also impact the psychological wellbeing of the health care worker.

Overall, despite still being within the disease's incubation period, participants' feelings of risk upon return were generally not related to biological risk but rather focused on social risks related to public perceptions of them as 'risk-bodies' out of place in their home countries. The factors contributing to the development of stigma, 
including the influence of mass media, will be examined further in the following discussion section.

\section{DISCUSSION}

For international health care workers, leaving West Africa and returning to their home countries did not mean the end of risk. Due to the 21-day incubation period of the virus the participants existed in a kind of limbo until they could be fully cleared from developing the disease. However, surprisingly, participants were not particularly worried about the biological risk at this time, as most were quite confident that they had not contracted Ebola, and were also confident that they were not infectious to others due to a lack of symptoms. Instead, biological risks became secondary to the more dominant social risks, as fearful social representations of the disease and public discourses of contagion and blame led the returning health care workers to become tangible embodiments of the disease in their home countries, regardless of actual infectious status.

Although infectious diseases such as plague, leprosy, cholera, the Human Immunodeficiency Virus (HIV) and now Ebola are known for the social stigma that has developed around them, the stigmatization of associated health care workers is a lesser-explored phenomenon. Other studies have shown stigmatisation of local health workers during Ebola outbreaks (Bell et al., 2017; Guimard et al., 1999; Hewlett \& Hewlett, 2005; Kinsman, 2012) and during SARS (Bai et al., 2004; Koh et al., 2005; Nickell et al., 2004). Findings of courtesy stigma have been found in health and social service workers who provide care to stigmatized patient groups such as those with the acquired immunodeficiency syndrome (AIDS) (Mill et al., 2013; Snyder, Omoto, \& Crain, 1999) and the mentally ill (Sadow, Ryder, \& Webster, 2002). Our study found the experience of stigma of returning health care workers to be an international phenomenon as it was experienced almost unanimously in participants, from Japan to Uganda to Denmark to Canada and beyond, and extended to family members of health care workers in some cases, expanding the recent findings of Gershon et al. (2016) and Haggman et al. (2016). This stigma was geographically widespread, and occurred irrespective of the presence or absence of the actual disease in the country, highlighting the detachment of stigma from any reality of disease transmission.

This raises questions related to the underlying dynamics of the development of courtesy stigma. In their examination of stigma related to HIV and AIDS, Parker and Aggelton (2003) highlight how the social process of stigmatization 'plays a key role in producing and reproducing relations of power and control'(p. 16) rather than simply being a result of holding correct or incorrect facts on disease transmission. The development of stigma around international health care workers in this study, a group not usually stigmatized, appears to have developed as a result of various societal power dynamics at play during the outbreak including distrust of government, political manipulation of quarantine policies, contradictory risk messages coming 
from media and public health bodies, and fears for the security and integrity of the borders of nation-states related to anxiety around globalization.

In this study, media messages appear to contribute to a fear reaction in family members and the public, which subsequently contributed to feelings of stigma in the international health care workers. According to Ungar (1998), the media may alternate between panic-inducing and panic-appeasing messages within the course of an outbreak. An analysis of public opinion polls in the US during the outbreak found a disproportionately high level of concern about the risk of contracting Ebola among the public, which was related to a lack of clear understanding or belief about how the disease spreads, coupled with overwhelming media coverage - the three main media channels in the country aired over 1000 segments about Ebola in a few weeks' span between October and November 2014 (SteelFisher, Blendon, \& Lasala-Blanco, 2015). SteelFisher and colleagues also note the political undertones to the public fear, including lack of trust in public health officials underlying a more generalized distrust of science and government (ibid.).

The high profile returns of a number of international health care workers to the US (whether infected or not) created a clear link between health care workers and the disease in the eyes of the public. One example of this was the forcible quarantine of healthy nurse Kaci Hickox on her return from West Africa. The episode demonstrated both media hysteria and an incoherent quarantine policy constructed more by politics (namely US mid-term elections) than by public health science. The media labeling of Hickox as "the Ebola nurse" (Hickox, 2014) despite the fact that she had never had Ebola demonstrated public attempts to 'other' her, and embody their fears within an easily identifiable source. Hickox faced extremes of public scorn, anger and ridicule as she tried to advocate for an evidence-based approach to quarantine policies. Participants in this study were also impacted by similar negative public sentiment, both through the reactions of those close to them, as well as during contact with the general public, including discouraging and abusive comments left on social media sites.

The experiences of returning health care workers in this study provided a particularly overt example of the narratives of 'blame' and 'contagion' seen in past courtesy stigma research (Corrigan \& Miller, 2004), with the outbreak narrative that formed during this crisis playing a role in the development of stigma. Wald (2007) describes how the development of 'outbreak narratives' are used to construct communities of insiders and outsiders, with infectious disease outbreaks becoming the basis of border-bound and border-building efforts to externalize disease. She highlights the impacts of such outbreak narratives - including influencing what information is disseminated, changing behavior and contagion routes, disrupting economies, and promoting or mitigating stigma. Social representations of disease play a strong role in forming the outbreak narrative. Previous analyses of social representations of both AIDS and Ebola have found that rhetorical constructions of these diseases, framed by 
preconceived beliefs about Africa as a 'dark continent' with predatorial viruses, shape public responses to global public health challenges (Grove \& Zwi, 2006; Joffe \& Haarhoff, 2002; Weldon, 2001). Themes of globalization also arose in their study, as did a feeling that should Ebola escape to the West it would be quickly contained by Western modern science. This narrative was partly shattered however in the West African outbreak, as the appearance of Ebola in the West and its transmission in modern health facilities suggested to the public a breach of containment measures on multiple levels - from equipment, to policies and procedures, to public health directives, to the sanitary borders of nation-states. This signaled that 'experts' did not have the situation under control, and reinforced an existing element of distrust of public health messages. Moreover, attempts of the media to link Ebola to other dreaded fears in the USA with headlines such as 'Ebola as a ISIS Bioweapon?' (Dorminey, 2014) and 'U.S. general warns Ebola could cross U.S. southern border' (Dinan \& Boyer, 2014) is also revealing of a more pervasive social fear of threats to the integrity of the safe boundaries of the nation-state, immigration, and the impacts of globalization. This is similar to past occurrences of stigma which were infused with undercurrents of globalization anxiety including that of Haitians during the early days of HIV (Castro \& Farmer, 2005), Mexicans during H1N1 flu outbreak (Sparke \& Anguelov, 2012), and Chinese during SARS (Eichelberger, 2007).

The impacts of this courtesy stigma were significant in this study. Similar to the difficult experiences with homecoming noted by Gershon et al. (2016), stigma and a perceived negative public attitude led to feelings of disappointment, sadness, anger and frustration among participants. It created high levels of anxiety and distress in family members. It also created practical challenges such as difficulty finding a place to live upon their return. Beyond these individual impacts, in a number of cases courtesy stigma contributed to a decision not to participate further in the Ebola response, an impact which may have significant public health implications in terms of response capacity should it recur in a future large scale infectious disease outbreak.

Some limitations to this study deserve mentioning, including the timing of the interviews, which while occurring within 1-2 months of completing the mission added to the accuracy of recall, but may have impacted the findings as participants may not have had time to fully reflect and process their experiences. The timing also limits the findings of courtesy stigma to the immediate post-mission period, and it is not known if or for how long the experience of stigma persisted, nor does this study allow for an understanding of longer-term impacts such as post-traumatic stress disorder. In addition to self-selection bias, participants may have been constrained due to fatigue, emotionality, lack of trust in the researcher, or a social desirability bias including fear for their or their organization's reputation. As only one out of eleven participants spoke English as a first language, this may have constrained full expression of ideas or resulted in misunderstandings. 
On a policy level, this study highlights the need for increased proactive support for health care workers and their families. While all participants were aware that psychological support was available to them, there was no proactive follow-up or contact from the sending organization's psychosocial support department during the 21 days or beyond. Given the common experiences of stigma and exhaustion in this study and knowing the significant rates of post-traumatic stress disorder in health care workers that occurred following the SARS outbreak (Chan \& Huak, 2004; Maunder, 2006; Wu et al., 2009), more proactive and longer-term psychosocial support would be warranted in future outbreaks of this nature. The opinions and emotions of family members had a strong impact on participants, including on their decision to continue working in the outbreak, however no proactive information or support was provided to family members. Increased and ongoing dialogue with family by the sending organization, and other forms of informational or psychological support, may mitigate risk feelings in family members by building their trust in the organization, and may help to overcome the negative influence of media reports. Lastly, media organizations must take responsibility for their role in contributing to unrealistic public fears, and must strive for more balanced and responsible reporting in future outbreaks. Overall, it is hoped that a better understanding of the phenomenon of courtesy stigma, its social determinants, and its impacts on this important group of health care workers may contribute to more effective support for outbreak responders in the future.

\section{Acknowledgements}

We would like to thank all the participants for their time and contribution to this study. 


\section{References}

Attride-Stirling, J. (2001). Thematic networks: An analytic tool for qualitative research. Qualitative Research, 1(3), 385-405.

Bai, Y., Lin, C.-C., Lin, C.-Y., Chen, J.-Y., Chue, C.-M., \& Chou, P. (2004). Survey of stress reactions among health care workers involved with the SARS outbreak. Psychiatric Services, 55(9), 1055-1057.

BBC. (2014). Ebola outbreak: Guinea health team killed. [Internet] https://goo.gl/C6tjSx accessed 22 Dec 2017.

Bell, S. A., Munro-Kramer, M. L., Eisenberg, M. C., Williams, G., Amarah, P., \& Lori, J. R. (2017). "Ebola kills generations": Qualitative discussions with Liberian healthcare providers. Midwifery, 45, 44-49.

Bryman, A. (2015). Social research methods: Oxford university press.

Castro, A., \& Farmer, P. (2005). Understanding and Addressing AIDS-Related Stigma: From Anthropological Theory to Clinical Practice in Haiti. American Journal of Public Health, 95(1), 53-59.

Chan, A. O., \& Huak, C. Y. (2004). Psychological impact of the 2003 severe acute respiratory syndrome outbreak on health care workers in a medium size regional general hospital in Singapore. Occupational Medicine, 54(3), 190196.

Corrigan, P. W., \& Miller, F. E. (2004). Shame, blame, and contamination: A review of the impact of mental illness stigma on family members. Journal of Mental Health, 13(6), 537-548.

Dinan, S., \& Boyer, D. (2014). U.S. general warns Ebola could cross U.S. southern border. [Internet] https://goo.gl/c1h74G Accessed 22 Dec 2017: Washington Post.

Dorminey, B. (2014). Ebola As ISIS Bio-Weapon?

Eichelberger, L. (2007). SARS and New York's Chinatown: the politics of risk and blame during an epidemic of fear. Social Science \& Medicine, 65(6), 12841295.

Gee, S., \& Skovdal, M. (2017a). Navigating 'riskscapes': The experiences of international health care workers responding to the Ebola outbreak in West Africa. Health \& place, 45, 173-180.

Gee, S., \& Skovdal, M. (2017b). The role of risk perception in willingness to respond to the 2014-2016 West African Ebola outbreak: a qualitative study of international health care workers. Global health research and policy, 2(1), 21.

Germain, J., Harris, J., Mackay, S., \& Maxwell, C. (2017). Why should we use online research methods? Four doctoral health student perspectives. Qualitative Health Research, 1049732317721698.

Gershon, R., Dernehl, L. A., Nwankwo, E., Zhi, Q., \& Qureshi, K. (2016). Experiences and Psychosocial Impact of West Africa Ebola Deployment on US Health Care Volunteers. PLoS Currents, 8 doi: 10.1371/currents.outbreaks.c7afaae124e35d2da39ee7e07291b6b5. 
Goffman, E. (1963). Stigma: notes on the management of spoiled identity. Englewood Cliffs, N.J.: Prentice-Hall.

Grove, N. J., \& Zwi, A. B. (2006). Our health and theirs: forced migration, othering, and public health. Social Science \& Medicine, 62(8), 1931-1942.

Guimard, Y., Bwaka, M. A., Colebunders, R., Calain, P., Massamba, M., De Roo, A., ... Ndaberey, D. E. (1999). Organization of patient care during the Ebola hemorrhagic fever epidemic in Kikwit, Democratic Republic of the Congo, 1995. Journal of Infectious Diseases, 179(Supplement 1), S268-S273.

Haggman, H., Kenkre, J., \& Wallace, C. (2016). Occupational health for humanitarian aid workers in an Ebola outbreak. Journal of Research in Nursing, 21(1), 2236.

Hewlett, B. L., \& Hewlett, B. S. (2005). Providing care and facing death: nursing during Ebola outbreaks in central Africa. Journal of Transcultural Nursing, 16(4), 289-297.

Hickox, K. (2014). Stop calling me 'the Ebola nurse'.

Ho, S. M. Y., Kwong-Lo, R. S. Y., Mak, C. W. Y., \& Wong, J. S. (2005). Fear of severe acute respiratory syndrome (SARS) among health care workers. Journal of consulting and clinical psychology, 73(2), 344.

Joffe, H., \& Haarhoff, G. (2002). Representations of far-flung illnesses: the case of Ebola in Britain. Social Science \& Medicine. doi:10.1016/S02779536(01)00068-5

Kasperson, R. E., Renn, O., Slovic, P., Brown, H. S., Emel, J., Goble, R., . . Ratick, S. (1988). The Social Amplification of Risk: A Conceptual Framework. Risk Analysis, 8(2), 177-187. doi:10.1111/j.1539-6924.1988.tb01168.x

Kinsman, J. (2012). "A time of fear": local, national, and international responses to a large Ebola outbreak in Uganda. Globalization and Health, 8(1), 15.

Koh, D., Lim, M. K., Chia, S. E., Ko, S. M., Qian, F., Ng, V., .. Tang, H. K. (2005). Risk perception and impact of Severe Acute Respiratory Syndrome (SARS) on work and personal lives of healthcare workers in Singapore: what can we learn? Medical care, 43(7), 676-682.

Kvale, S. (1983). The qualitative research interview: A phenomenological and a hermeneutical mode of understanding. Journal of phenomenological psychology, 14(2), 171.

Malterud, K., Siersma, V. D., \& Guassora, A. D. (2016). Sample size in qualitative interview studies: guided by information power. Qualitative Health Research, 26(13), 1753-1760.

Maunder, R. G. (2006). Long-term psychological and occupational effects of providing hospital healthcare during SARS outbreak. Emerging Infectious Disease, 12(12), 1924-1932.

Mill, J., Harrowing, J., Rae, T., Richter, S., Minnie, K., Mbalinda, S., \& HepburnBrown, C. (2013). Stigma in AIDS nursing care in sub-Saharan Africa and the Caribbean. Qualitative Health Research, 23(8), 1066-1078.

Nickell, L. A., Crighton, E. J., Tracy, C. S., Al-Enazy, H., Bolaji, Y., Hanjrah, S., . . . Upshur, R. E. (2004). Psychosocial effects of SARS on hospital staff: survey 
of a large tertiary care institution. Canadian medical association journal, 170(5), 793-798.

Nossiter, A. (2014). Fear of Ebola Breeds a Terror of Physicians. The New York Times. Kolo Bengou, Guinea. : [Internet] https://nyti.ms/2kcE3ji Accessed 22 Dec 2017.

Parker, R., \& Aggleton, P. (2003). HIV and AIDS-related stigma and discrimination: a conceptual framework and implications for action. Social Science \& Medicine, 57(1), 13-24.

Phillips, R., Benoit, C., Hallgrimsdottir, H., \& Vallance, K. (2012). Courtesy stigma: a hidden health concern among front-line service providers to sex workers. Sociology of Health \& Illness, 34(5), 681-696. doi:10.1111/j.14679566.2011.01410.x

Richards, L. (1999). Data alive! The thinking behind NVivo. Qualitative Health Research, 9(3), 412-428.

Sadow, D., Ryder, M., \& Webster, D. (2002). Is education of health professionals encouraging stigma towards the mentally ill? Journal of Mental Health, 11(6), 657-665.

Simons, L., Lathlean, J., \& Squire, C. (2008). Shifting the focus: sequential methods of analysis with qualitative data. Qualitative Health Research, 18(1), 120-132.

Sixsmith, J., Boneham, M., \& Goldring, J. E. (2003). Accessing the community: Gaining insider perspectives from the outside. Qualitative Health Research, 13(4), 578-589.

Skovdal, M., \& Cornish, F. (2015). Qualitative Research for Development: A guide for practitioners. Rugby: Practical Action Publishing.

Snyder, M., Omoto, A. M., \& Crain, A. L. (1999). Punished for their good deeds: Stigmatization of AIDS volunteers. American Behavioral Scientist, 42(7), 1175-1192.

Sparke, M., \& Anguelov, D. (2012). H1N1, globalization and the epidemiology of inequality. Health \& place, 18(4), 726-736.

SteelFisher, G. K., Blendon, R. J., \& Lasala-Blanco, N. (2015). Ebola in the United States - public reactions and implications. New England Journal of Medicine, 373(9), 789-791.

Tam, C. W., Pang, E. P., Lam, L. C., \& Chiu, H. F. (2004). Severe acute respiratory syndrome (SARS) in Hong Kong in 2003: stress and psychological impact among frontline healthcare workers. Psychological medicine, 34(07), 11971204.

Ungar, S. (1998). Hot Crises and Media Reassurance: A Comparison of Emerging Diseases and Ebola Zaire. The British Journal of Sociology.

Vetter, P., Dayer, J.-A., Schibler, M., Allegranzi, B., Brown, D., Calmy, A., . . . Henderson, D. (2016). The 2014-2015 Ebola outbreak in West Africa: Hands On. Antimicrobial Resistance \& Infection Control, 5(1), 17.

Wald, P. (2007). Contagious: cultures, carriers, and the outbreak narrative: Duke University Press. 
Weldon, R. A. (2001). The rhetorical construction of the predatorial virus: A Burkian analysis of nonfiction accounts of the Ebola virus. Qualitative Health Research, 11(1), 5-25.

WHO. (2015). Health worker Ebola infections in Guinea, Liberia and Sierra Leone A preliminary report. [Internet] https://goo.gl/7hLUkg Accessed 22 Dec 2017.

Wu, P., Fang, Y., Guan, Z., Fan, B., Kong, J., Yao, Z., . . Lu, J. (2009). The psychological impact of the SARS epidemic on hospital employees in China: Exposure, risk perception, and altruistic acceptance of risk. The Canadian Journal of Psychiatry, 54(5), 302-311. 
